\title{
Continuous EEG monitoring after brain tumor surgery
}

\section{Kristin Elf ${ }^{1}$ - Elisabeth Ronne-Engström ${ }^{2} \cdot$ Robert Semnic $^{3}$ - Elham Rostami-Berglund ${ }^{2} \cdot$ Jimmy Sundblom $^{2}$. Maria Zetterling ${ }^{2}$}

Received: 1 April 2019 / Accepted: 11 June 2019 / Published online: 6 July 2019

(C) The Author(s) 2019

\begin{abstract}
Background Prolonged seizures generate cerebral hypoxia and increased intracranial pressure, resulting in an increased risk of neurological deterioration, increased long-term morbidity, and shorter survival. Seizures should be recognized early and treated promptly.

The aim of the study was to investigate the occurrence of postoperative seizures in patients undergoing craniotomy for primary brain tumors and to determine if non-convulsive seizures could explain some of the postoperative neurological deterioration that may occur after surgery.

Methods A single-center prospective study of 100 patients with suspected glioma. Participants were studied with EEG and video recording for at least $24 \mathrm{~h}$ after surgery.

Results Seven patients (7\%) displayed seizure activity on EEG recording within $24 \mathrm{~h}$ after surgery and another two patients (2\%) developed late seizures. One of the patients with early seizures also developed late seizures. In five patients (5\%), there were nonconvulsive seizures. Four of these patients had a combination of clinically overt and non-convulsive seizures and in one patient, all seizures were non-convulsive. The non-convulsive seizures accounted for the majority of total seizure time in those patients. Non-convulsive seizures could not explain six cases of unexpected postoperative neurological deterioration. Postoperative ischemic lesions were more common in patients with early postoperative seizures.

Conclusions Early seizures, including non-convulsive, occurred in $7 \%$ of our patients. Within this group, non-convulsive seizure activity had longer durations than clinically overt seizures, but only $1 \%$ of patients had exclusively non-convulsive seizures. Seizures were not associated with unexpected neurological deterioration.
\end{abstract}

Keywords Brain tumor surgery $\cdot$ Postoperative seizures $\cdot$ Non-convulsive seizures $\cdot$ EEG monitoring

\section{Abbreviations}

AED Anti-epileptic drug

5-ALA 5-Aminolevulinic acid

CT Computed tomography

This article is part of the Topical Collection on Tumor - Glioma

Electronic supplementary material The online version of this article (https://doi.org/10.1007/s00701-019-03982-6) contains supplementary material, which is available to authorized users.

Maria Zetterling

maria.zetterling@neuro.uu.se

1 Department of Neuroscience, Clinical Neurophysiology, Uppsala University, University Hospital, S-751 85 Uppsala, Sweden

2 Department of Neuroscience, Neurosurgery, Uppsala University, University Hospital, S-751 85 Uppsala, Sweden

3 Department of Surgical Sciences, Radiology, Uppsala University, S-751 85 Uppsala, Sweden
cEEG Continuous electro-encephalography

ICE Intracerebral EEG

ICP Intracranial pressure

MRI Magnetic resonance imaging

WHO World Health Organization

\section{Introduction}

Seizure activity is an energy-demanding process with a risk of secondary neuronal injury. Prolonged seizures generate cerebral hypoxia and increased intracranial pressure resulting in an increased risk of neurological deterioration, longer hospital stay, increased long-term morbidity, and shorter survival [10, $23,26,28]$. It is thus crucial to find these patients at risk and treat them promptly.

Patients with brain tumors are prone to develop epileptic seizures [33]. Seizure is the first symptom in $80 \%$ of patients 
with low-grade gliomas (WHO grade II) [6], but is less common as the initial symptom in patients with high-grade gliomas (WHO grades III and IV) [37]. During the course of the disease, more than half of patients with high-grade gliomas develop seizures [37]. Seizures in patients with brain tumors are associated with progression of the disease and shorter survival $[3,6,35]$.

Earlier studies have found varying rates of postoperative seizures after surgery for primary brain tumors, from $2 \%$ up to $34 \%$ [1, 10, 12, 16, 19, 20, 28, 31, 33, 37]. Postoperative seizures may occur whether or not the patients had seizures prior to surgery $[10,12,20,28]$, and the occurrence of postoperative seizures for the individual patient is difficult to predict. Today, the incidence of non-convulsive seizures after craniotomy for primary brain tumors is not known. Previous studies have shown that non-convulsive status epilepticus occurred in $2 \%$ of brain tumor patients [27]. In an intensive care setting, non-convulsive seizures were detected in $23 \%$ and non-convulsive status epilepticus in $12 \%$ of patients with brain tumors [8]. There has been no previous consecutive series of continuous EEG (cEEG) monitoring after brain tumor surgery and hence the true seizure occurrence of nonconvulsive seizures is unknown.

After craniotomy for brain tumors, $7-17 \%[5,7,14,25]$ of the patients suffer from a decline in the neurological function. In some of these patients, non-convulsive seizures may be a treatable cause of the deterioration.

The aim of the present study was to investigate the occurrence of postoperative seizures including non-convulsive seizures in patients undergoing craniotomy for primary brain tumors and to find out if non-convulsive seizures could explain some of the postoperative neurological deterioration that may occur after surgery.

\section{Methods and materials}

\section{Patients}

Adult patients ( $>18$ years of age) with a radiological suspicion of low- or high-grade glioma (WHO grades II-IV) planned for surgery at the Department of Neurosurgery, Uppsala University Hospital during the period 22 August 2016 to 7 December 2017 were prospectively included in the study. Informed consent was obtained prior to participation. The study was approved by the institutional ethics review board (2016/112).

Patients treated with anti-epileptic drugs (AED) prior to surgery continued with the ordinary dose. Intraoperative AED prophylaxis was administrated in awake surgery but in other cases according to the preferences of the surgeon. Before surgery, patients with epilepsy were optimized regarding seizure frequency with AED adjustment. No patient with an uncontrolled seizure situation was considered for surgery.

Patients went through preoperative magnetic resonance imaging (MRI), and postoperative MRI was performed within $48 \mathrm{~h}$ after surgery. In high-grade tumors, contrast enhancement on T1-weighted turbo spin echo sequences and, in low-grade tumors, high signal intensity on T2- fluid-attenuated inversion recovery (FLAIR) sequences were considered as tumor tissue. Postoperative MRI was used to identify any new postoperative ischemic areas.

In awake surgery, dexmedetomidine (Dexdor, Orion Pharma, Danderyd, Sweden) was administrated if required. Otherwise, general intravenous anesthesia with propofol (Diprivan, Ballerup, Denmark) and remifentanil (Remifentanil, TEVA Sweden AB, Helsingborg, Sweden) was used. 5-Aminolevulinic acid (5-ALA) (Gliolan, Medac Pharma, Varberg, Sweden) was used in patients with presumed high-grade (contrast enhancing) tumors if total resection was the goal of surgery.

All patients with postoperative seizures or neurological deterioration went through a $\mathrm{CT}$ scan to rule out a postoperative hematoma.

\section{EEG electrodes and postoperative continuous EEG video monitoring}

After surgery, before dressing and with the patient still anesthetized, 11 needle electrodes (Technomed, Cephalon, Maastricht, the Netherlands) were attached to the scalp: bifrontal (F3, F4), bitemporal (T3, T4), biparietal (P3, P4), bioccipital $(\mathrm{O} 1, \mathrm{O} 2)$, one midline $(\mathrm{Cz})$, one ground, and one reference (in front of and behind $\mathrm{Cz}$, respectively).

EEG and video monitoring (Nicolet Monitor, Natus Neuro, Middleton, USA) were initiated immediately upon arrival at postoperative care unit and continued until discharge to the general ward, as a rule, $24 \mathrm{~h}$ after surgery. EEG data were collected on the general hospital server utilizing the NicoletOne System, and interpretation was performed from a remote reading station with the NicoletOne Reader. All raw cEEG was read continuously, but EEG trends (amplitude integrated EEG and spectral edge) were used to facilitate interpretation and to reduce the risk of missing important episodes due to reader fatigue. The modified Salzburg Consensus Criteria were used for definition of non-convulsive seizures and status epilepticus [24]. The overall terminology and classification applied was the American Clinical Neurophysiology Society's critical care standardized terminology [18].

\section{Statistics}

To calculate differences between groups, Mann-Whitney $U$ test for continuous and categorical variables and Fisher exact two-tailed test for proportions were used in Statistica, version 
13.2 (StatSoft, Inc. Tulsa, OK, USA). A $p$ value $<0.05$ was considered statistically significant.

\section{Results}

\section{Clinical data}

One hundred patients, 59 men and 41 women, underwent tumor resection. The mean age \pm SD was $53.5( \pm 16.2)$ years. Eleven patients went through awake surgery and in 25 patients, perioperative neurophysiology monitoring was carried out. In 21 patients, 5-ALA was used. The most common preoperative symptoms were epileptic seizures (52\%) followed by cognitive deficits $(25 \%)$. In $89 \%$ of the cases, the tumors involved the frontal and/ or temporal lobes. The histopathological diagnoses were high-grade gliomas WHO grades IIIIV in $69 \%$ and WHO grade II gliomas in $24 \%$ of the patients. Preoperative symptoms and tumor locations are presented in Table 1 and the final diagnosis in Table 2. Median (25th-75th percentile) preoperative tumor volume was $32.4 \mathrm{~cm}^{3}(11.2-$

Table 1 Preoperative symptoms and tumor locations in 100 patients

\begin{tabular}{|c|c|}
\hline Symptom & $\%$ \\
\hline Seizures & 52 \\
\hline Cognitive deficit & 25 \\
\hline Language disturbances & 14 \\
\hline Motor deficit & 12 \\
\hline Visual field deficit & 7 \\
\hline Gait-coordination disturbance & 4 \\
\hline Headache & 19 \\
\hline Asymptomatic & 5 \\
\hline Patients with & $N$ \\
\hline No symptom & 5 \\
\hline One symptom & 63 \\
\hline Two symptoms & 26 \\
\hline Three symptoms & 6 \\
\hline Tumor location & $\%$ \\
\hline Frontal & 33 \\
\hline Temporal & 27 \\
\hline Parietal & 4 \\
\hline Occipital & 2 \\
\hline Insular* & 12 \\
\hline Frontal + corpus callosum/gyrus cinguli & 8 \\
\hline Frontal-parietal-temporal & 1 \\
\hline Temporal-occipital & 4 \\
\hline Parietal-temporal & 4 \\
\hline Parietal-occipital & 4 \\
\hline Midline & 1 \\
\hline
\end{tabular}

*Fronto-insular $n=2$, temporal-insular $n=1$, fronto-temporal-insular $n=$ 8 , fronto-temporal-insular $+\operatorname{central} n=1$
Table 2 Tumor diagnosis in 100 patients

\begin{tabular}{lll}
\hline Tumor diagnosis & $N$ & $\%$ \\
\hline WHO grade IV & 48 & 50 \\
Glioblastoma & 2 & \\
Gliosarcoma & & 19 \\
WHO grade III & 11 & \\
Anaplastic astrocytoma & 6 & \\
Anaplastic oligodendroglioma & 1 & \\
Anaplastic Ependymoma & 1 & \\
Anaplastic pleomorphic xantoastroctoma & & \\
WHO grade II & 9 & \\
Astrocytoma & 13 & \\
Oligodendroglioma & 1 & \\
Ependymoma & 1 & \\
Not classified & & \\
WHO grade I & 1 & \\
Pilocytic astrocytoma & & \\
Metastasis & 1 & 4 \\
Adenocarcinoma & 1 & \\
Gastric carcinoma & & \\
Other & & \\
B cell lymphoma & & \\
Unclassified & & \\
\hline
\end{tabular}

74.5). Median (25th-75th percentile) resection grade was $96.5 \%(72.5-100)$.

\section{Preoperative epilepsy and AED}

Fifty-two percent of patients had seizures preoperatively. In another $3 \%$ of patients, there was suspicion, but not a definitive diagnosis of epileptic seizures. Fifty-three percent used AED before surgery. In one patient, the indication for prescription of AED was a pain. Epileptic manifestations and AED treatments are presented in Online Resource. Three patients were diagnosed with epilepsy in childhood. Two of these were still on anti-epileptic drugs and showed a sporadic and low frequency of focal seizures with impaired consciousness. In one patient, epilepsy terminated in childhood and no AED had been used since.

\section{Intraoperative AED prophylaxis and intraoperative seizures}

Sixteen percent of patients received intraoperative AED prophylaxis with fosphenytoin or levetiracetam. One of these developed EEG-verified seizures during the first $24 \mathrm{~h}$ after surgery.

Two patients experienced intraoperative seizures. One patient developed bilateral tonic-clonic seizures after subcortical 
motor stimulation during general anesthesia and the other patient showed focal seizures during awake surgery.

\section{Seizures within $24 \mathrm{~h}$ after surgery}

Seven percent of patients displayed seizure activity on cEEG recording within $24 \mathrm{~h}$ after surgery. Tables 3 and 4 summarize the findings in these patients. Two of the 7 patients had a preoperative diagnosis of epilepsy and one of the 7 patients was treated with AED.

\section{Non-convulsive seizures}

Seizure activity in the EEG without any clinical signs of seizures (non-convulsive seizure) was detected in five (5\%) of patients. For details, see Table 3. Mostly, non-convulsive seizures preceded the onset of clinical seizures but there were isolated nonconvulsive seizures as well. In one patient, there was $42 \mathrm{~min}$ of unnoticed non-convulsive seizures. In one patient, the recording was stopped due to an examination and the seizure activity started during this time. Therefore, the seizure time is presented as an interval, the shortest to the longest time possible. The summarized duration of non-convulsive seizure represented $72-78 \%$ of total seizure time.

\section{Late postoperative seizures in patients who were seizure free during the initial $\mathbf{2 4} \mathrm{h}$ after surgery}

Two patients were seizure free during the initial 24-h EEG monitoring period but developed late seizures (see Tables 3 and 4). In addition, one of the patients with early seizures also developed late seizures that are described in Online Resource.

\section{Clinical suspicion of postoperative seizures but no seizure activity on EEG}

In four patients, there were clinical suspicions of seizures during the EEG monitoring time but no concomitant ictal EEG pattern was found. The symptoms in those patients were suspected of focal motor seizures in three patients and focal seizures with impaired consciousness in one patient (Table 4).

\section{Clinical factors}

There were no differences in tumor volumes, resection grades, tumor locations, diagnosis, or the use of 5-ALA for patients who developed seizures postoperatively and for those who did not. On postoperative MRI, a larger proportion of patients with early postoperative seizures showed ischemic lesions $(3 / 7,43 \%)$, compared to patients without early seizures (11/ $93,12 \%)$. An epilepsy diagnosis earlier in life, was present in 2 of $7(29 \%)$ patients with early postoperative seizures and in
1 of the $93(1.1 \%)$ patients without early postoperative seizures.

\section{Postoperative neurological deterioration}

Six patients deteriorated postoperatively during the EEG monitoring time. The symptoms in these patients were paresis in one hand $(n=1)$, dysphasia $(n=2)$, dysphasia, hemiparesis and decreased the level of consciousness ( $n=1$ ), dilatation of one pupil and hemiparesis $(n=1)$, and confusion $(n=1)$. CT scanning did not reveal any explanation and non-convulsive seizures were considered a possible cause of deterioration at that time. However, none of these patients exhibited seizure activity on EEG recording, and a specific period of postictal slowing could not be identified. Therefore, the postoperative neurological deterioration in those cases could neither be explained by nonconvulsive seizures nor by subtle, non-convulsive seizures followed by postictal symptoms.

\section{Postoperative ischemia, hematoma, and second surgery}

In 14 patients (14\%), postoperative MRI showed a new ischemic lesion. Nine of these patients $(64 \%)$ deteriorated neurologically after surgery but there was complete regression of postoperative neurological deficits in 8 patients and almost complete regression in 1 patient. Three patients underwent a second surgery. One patient developed a postoperative hematoma in the surgical field which was evacuated $24 \mathrm{~h}$ after the primary surgery when a hemiparesis developed. Another patient was reintubated directly after the primary surgery due to a decreased level of consciousness and received an intraparenchymal pressure monitoring device. The third patient displayed a generalized tonic-clonic seizure and decreased the level of consciousness. A CT scanning revealed a distant hematoma in the posterior fossa and the patient was subjected to an external intraventricular drainage procedure.

\section{Discussion}

In this study, we monitored the occurrence of seizure activity on continous EEG recording the first $24 \mathrm{~h}$ after surgery for primary brain tumors in 100 consecutive cases. The aim was to estimate the occurrence of convulsive and non-convulsive seizures and to determine if they were related to postoperative neurological deterioration. We found that seizures occurred in $7 \%$ of patients within $24 \mathrm{~h}$ after surgery. Another $2 \%$ of patients developed late seizures after $24 \mathrm{~h}$ which required prolonged EEG monitoring time and one of the patients with early seizures also developed late seizures.

After surgery for brain tumors, it is not uncommon that the surgeon encounters a patient who has deteriorated 


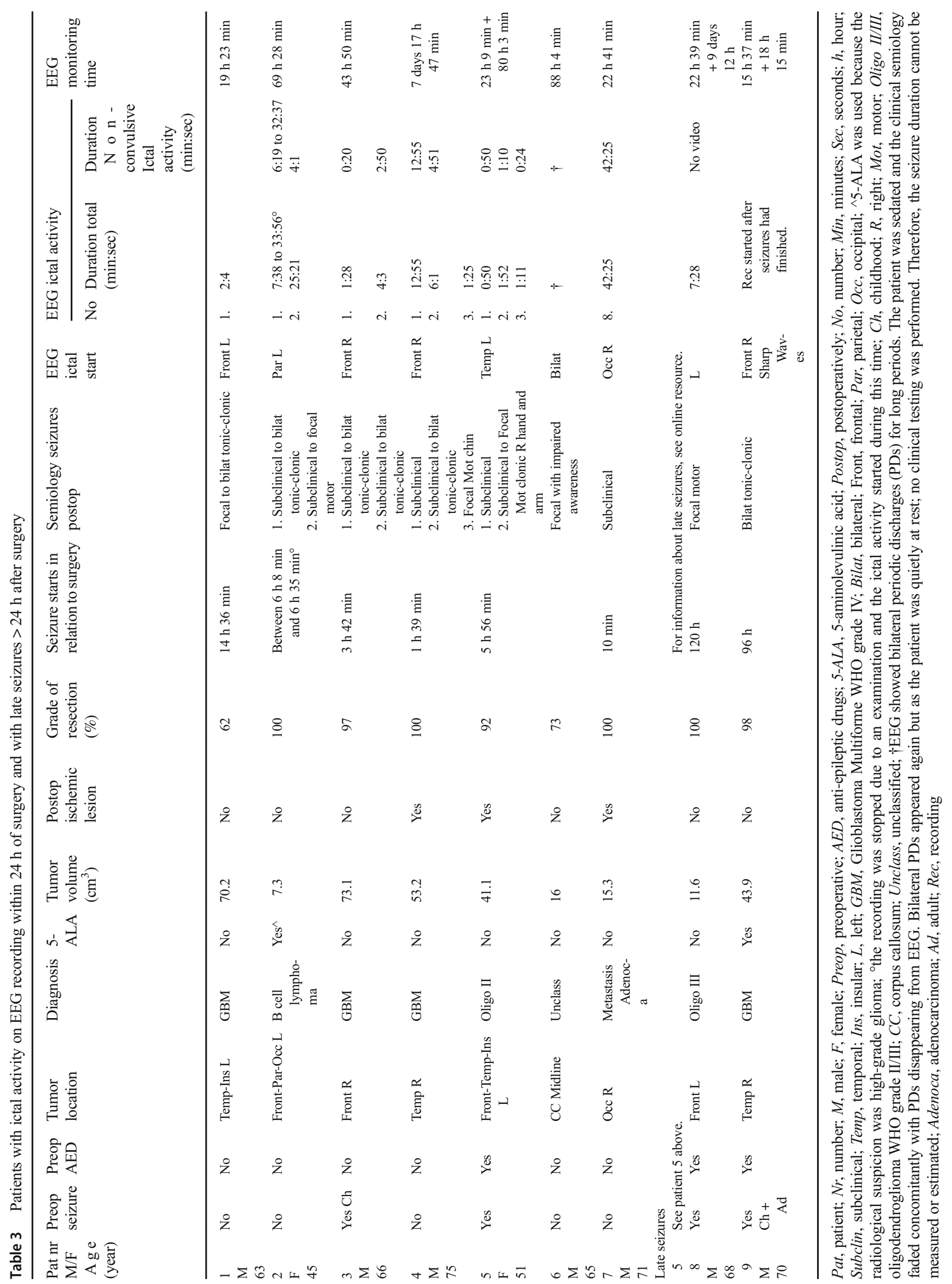


Table 4 A summary of the patients with ictal activity on continuous EEG or clinically suspected seizures

\begin{tabular}{|c|c|c|c|c|c|c|c|}
\hline Patient & $\begin{array}{l}\text { Postoperative } \\
\text { seizures }\end{array}$ & $\begin{array}{l}\text { Ictal activity in } \\
\text { EEG }\end{array}$ & Semiology & $\begin{array}{l}\text { Complicated clinical } \\
\text { course* }\end{array}$ & $\begin{array}{l}\text { Postop ischemic } \\
\text { lesion }\end{array}$ & Preoperative EP & AED \\
\hline 1 & Early $<24$ & Yes & Overt & Yes & No & No & No \\
\hline 2 & Early $<24$ & Yes & $\begin{array}{l}\text { Non-convulsive and } \\
\text { overt }\end{array}$ & Yes & No & No & No \\
\hline 3 & Early $<24$ & Yes & $\begin{array}{l}\text { Non-convulsive and } \\
\text { overt }\end{array}$ & No & No & $\begin{array}{l}\text { Yes } \\
\text { Childhood }\end{array}$ & No \\
\hline 4 & Early $<24$ & Yes & $\begin{array}{l}\text { Non-convulsive and } \\
\text { overt }\end{array}$ & Yes & Yes & No & No \\
\hline 5 & $\begin{array}{l}\text { Early and late } \\
>24 \mathrm{~h}\end{array}$ & Yes & $\begin{array}{l}\text { Non-convulsive and } \\
\text { overt }\end{array}$ & Yes & Yes & Yes & Yes \\
\hline 6 & Early & Yes & $\begin{array}{l}\text { Non-convulsive and } \\
\text { subtle }\end{array}$ & Yes & No & No & No \\
\hline 7 & Early $<24 \mathrm{~h}$ & Yes & Non-convulsive & No & Yes & No & No \\
\hline 8 & Late $>24 \mathrm{~h}$ & Yes & Overt & Yes & No & Yes & Yes \\
\hline 9 & Late $>24 \mathrm{~h}$ & No & Overt & Yes & No & $\begin{array}{l}\text { Yes } \\
\text { Childhood + } \\
\quad \text { adult }\end{array}$ & Yes \\
\hline 10 & $\begin{array}{l}\text { Clin suspected } \\
\quad<24 \mathrm{~h}\end{array}$ & No & Focal motor & No & No & Yes & Yes \\
\hline 11 & $\begin{array}{l}\text { Clin suspected } \\
\quad<24 \mathrm{~h}\end{array}$ & No & Focal motor & No & No & Yes & Yes \\
\hline 12 & $\begin{array}{l}\text { Clin suspected } \\
<24 \mathrm{~h}\end{array}$ & No & Focal motor & No & No & Yes & Yes \\
\hline 13 & $\begin{array}{l}\text { Clin suspected } \\
\quad<24 \mathrm{~h}\end{array}$ & No & Impaired consciousness & No & No & Yes & Yes \\
\hline
\end{tabular}

*A complicated clinical course was defined as prolonged stay in the intensive or intermediate ward or readmission to these because of complications Postop, postoperatively; Clin, clinically

neurologically. As a standard, an immediate CT scan is performed to rule out an expansive hematoma requiring evacuation. In some cases, such as surgery in connection to eloquent areas, the deterioration of a specific neurological function is expected. However, in other cases, the reason for the deterioration is unclear, and non-convulsive seizures are considered a possible cause. Since an acute EEG usually is difficult to arrange outside office time, the question of whether the patient should be treated with AED with potentially serious side effects [2], without prior EEG may appear. This study provides information about the occurrence of non-convulsive seizures in a consecutive group of patients with assumed primary brain tumors, information that could be useful in the above-described situation.

This is to our knowledge the first prospective study in which EEG monitoring was used after surgery for brain tumors in consecutive material. We found that altogether $9 \%$ of patients had seizures postoperatively. This is lower than what usually is reported in the literature, probably because we studied a consecutive material. Earlier studies reporting seizure incidence after brain tumor surgery have either been performed on high-risk groups in the intensive care setting [8, $13,22,29]$ or are retrospective studies without systematically EEG monitoring $[1,3,6,10,16,33-35]$. The incidence of convulsive seizures after craniotomy for primary brain tumors varies in different studies from 2 to $44 \%,[1,10,12,13,16,19$, $20,28,31,33,37]$. This variation could be explained by differences in patient selection, different observation times postoperatively, or differences in postoperative routines and thereby the ability to detect seizures.

This is also the first study to report of non-convulsive seizures in the acute phase after surgery of brain tumors. Previous studies were done in epilepsy-prone patients and/or patients in the intensive care unit $[8,13,22,29]$. These studies showed that non-convulsive status epilepticus occurred in $2 \%$ of brain tumor patients [27]. In the intensive care unit, non-convulsive seizures were detected in $23 \%$ and non-convulsive status epilepticus in $12 \%$ of patients with brain tumors [8]. In the neurointensive care unit, $18-34 \%$ of patients suffered from non-convulsive status epilepticus [22, 29], and nonconvulsive seizures were an important cause of an unexplained decrease in the level of consciousness [8]. We found a lower frequency of non-convulsive seizures (5\%). This seizure incidence is likely more useful in estimating the occurrence and the risk of postoperative seizes in brain tumor patients in general because our patient series was consecutively collected without any selection bias.

One question in our study was if seizure activity could explain some of the postoperative worsening of neurological function. However, among the six patients with an early 
unexplained postoperative decline in neurological function, no seizure activity was present in the cEEG recordings. This finding supports the conclusions that, in case of unexpected neurological deterioration, other causes than non-convulsive seizures should be excluded and treatment with anti-epileptic drugs may not be justified without prior EEG diagnosis. Another four patients displayed episodes of clinically suspect seizures but without seizure activity in the EEG. In such cases, shivering, tremor, and drug-induced myoclonia may be misinterpreted as a seizure. There is a possibility is that we underdiagnosed non-convulsive seizures because the nine surface electrodes used were too sparse to record very focal seizure activity. It is recommended to use at least 16 electrodes [17], but for this postoperative study of brain tumor patients, we gave priority to single-use needle electrodes in order to ensure sterility and to secure electrode contact under the head bandage. Therefore, we chose to reduce the number of electrodes to 11 .

Studies on patients during neurointensive care have shown a discrepancy in the occurrence of seizure activity recorded by intracerebral electrodes (ICE) and surface electrodes with a higher incidence of electrographic seizures detected by ICE compared to scalp EEG $[9,36]$. We did not use ICE, but such recordings may have been useful since two of our patients with unexplained deterioration showed patterns related to seizure activity registered by ICE.

Before surgery, low-grade glioma [19], cortical location [3, 6], temporal lobe involvement [3], and oligodendroglioma subtypes [6] have been identified as risk factors for preoperative seizures. For the individual patient, the occurrence of epileptic seizures acutely after craniotomy for a brain tumor is difficult to predict. Higher age [33, 34], small tumors [33], complete resections [33], and parietal lobe involvement [3] or diencephalic location [33] have been related to postoperative seizures. Regarding the influence of tumor grade, there are diverging results $[10,33]$. The occurrence of seizures before surgery $[1,13,19,28,34]$, especially if there is a long history of seizures [30] or if the seizures are focal [30] or uncontrolled [3], was positively correlated with seizures postoperatively. However, other studies showed no relationship between preoperative seizures or treatment with anti-epileptic drugs and postoperative seizures $[4,10,20,33]$.

Except for a tendency for more postoperative ischemic lesions in patients with early postoperative seizures, we did not discern differences in clinical factors between patients with or without seizures after surgery. This may be because the number of patients with postoperative seizures was too small to reliably calculate risk factors for this group.

A recent meta-analysis showed a beneficial effect for AED prophylaxis on reducing the incidence of early postoperative seizures [21] but today, there is no general consensus for AED prophylaxis in patients with a brain tumor and no prior seizures $[11,15,32,38]$. The three patients in this study who went through a second monitoring due to recurrent late seizures were on treatment with AED before surgery, but only one of the seven patients with early seizures used AED preoperatively.

To conclude, early postoperative seizures, including nonconvulsive seizures, occurred in $7 \%$ of our patients. Within this group, non-convulsive seizures had longer durations than clinically overt seizures. However, non-convulsive seizures were not the cause of unexplained postoperative deterioration in this patient series. In cases of unclear deterioration, other treatable causes should be excluded.

Acknowledgements The authors are thankful to Timothy Howells for language editing.

Funding This study received financial support from the Selanders Cancer Foundation and ALF research funds at the Uppsala University Hospital.

\section{Compliance with ethical standards}

Conflict of interest The authors declare that they have no conflict of interest.

Ethical approval All procedures performed in studies involving human participants were in accordance with the ethical standards of the institutional and/or national research committee (Regionala etikprövningsnämnden Uppsala 2016/112) and with the 1964 Helsinki Declaration and its later amendments or comparable ethical standards.

Informed consent Informed consent was obtained from all individual participants included in the study.

Open Access This article is distributed under the terms of the Creative Commons Attribution 4.0 International License (http:// creativecommons.org/licenses/by/4.0/), which permits unrestricted use, distribution, and reproduction in any medium, provided you give appropriate credit to the original author(s) and the source, provide a link to the Creative Commons license, and indicate if changes were made.

\section{References}

1. Bech KT, Seyedi JF, Schulz M, Poulsen FR, Pedersen CB (2018) The risk of developing seizures before and after primary brain surgery of low- and high-grade gliomas. Clin Neurol Neurosurg 169: 185-191. https://doi.org/10.1016/j.clineuro.2018.04.024

2. Borrelli EP, Lee EY, Descoteaux AM, Kogut SJ, Caffrey AR (2018) Stevens-Johnson syndrome and toxic epidermal necrolysis with antiepileptic drugs: an analysis of the US Food and Drug Administration Adverse Event Reporting System. Epilepsia 59: 2318-2324. https://doi.org/10.1111/epi.14591

3. Chaichana KL, Parker SL, Olivi A, Quinones-Hinojosa A (2009) Long-term seizure outcomes in adult patients undergoing primary resection of malignant brain astrocytomas. Clinical article. J Neurosurg 111:282-292. https://doi.org/10. 3171/2009.2.JNS081132

4. Chandra V, Rock AK, Opalak C, Stary JM, Sima AP, Carr M, Vega RA, Broaddus WC (2017) A systematic review of perioperative seizure prophylaxis during brain tumor resection: the case for a 
multicenter randomized clinical trial. Neurosurg Focus 43:E18. https://doi.org/10.3171/2017.8.FOCUS17442

5. Chang SM, Parney IF, McDermott M, Barker FG 2nd, Schmidt MH, Huang W, Laws ER Jr, Lillehei KO, Bernstein M, Brem H, Sloan AE, Berger M, Glioma Outcomes I (2003) Perioperative complications and neurological outcomes of first and second craniotomies among patients enrolled in the Glioma Outcome Project. J Neurosurg 98:1175-1181. https://doi.org/10.3171/jns.2003.98.6. 1175

6. Chang EF, Potts MB, Keles GE, Lamborn KR, Chang SM, Barbaro NM, Berger MS (2008) Seizure characteristics and control following resection in 332 patients with low-grade gliomas. J Neurosurg 108:227-235. https://doi.org/10.3171/JNS/2008/108/2/0227

7. Ciric I, Ammirati M, Vick N, Mikhael M (1987) Supratentorial gliomas: surgical considerations and immediate postoperative results. Gross total resection versus partial resection. Neurosurgery 21:21-26

8. Claassen J, Mayer SA, Kowalski RG, Emerson RG, Hirsch LJ (2004) Detection of electrographic seizures with continuous EEG monitoring in critically ill patients. Neurology 62:1743-1748

9. Claassen J, Perotte A, Albers D, Kleinberg S, Schmidt JM, Tu B, Badjatia N, Lantigua H, Hirsch LJ, Mayer SA, Connolly ES, Hripcsak G (2013) Nonconvulsive seizures after subarachnoid hemorrhage: multimodal detection and outcomes. Ann Neurol 74: 53-64. https://doi.org/10.1002/ana.23859

10. Dewan MC, White-Dzuro GA, Brinson PR, Thompson RC, Chambless LB (2016) Perioperative seizure in patients with glioma is associated with longer hospitalization, higher readmission, and decreased overall survival. J Neurosurg:1-9. https://doi.org/10. 3171/2015.10.JNS151956

11. Forsyth PA, Weaver S, Fulton D, Brasher PM, Sutherland G, Stewart D, Hagen NA, Barnes P, Cairncross JG, DeAngelis LM (2003) Prophylactic anticonvulsants in patients with brain tumour. Can J Neurol Sci 30:106-112

12. Foy PM, Copeland GP, Shaw MD (1981) The incidence of postoperative seizures. Acta Neurochir 55:253-264

13. Freund B, Probasco JC, Ritzl EK (2018) Seizure incidence in the acute postneurosurgical period diagnosed using continuous electroencephalography. J Neurosurg:1-7. https://doi.org/10.3171/2018.1. JNS171466

14. Gempt J, Forschler A, Buchmann N, Pape H, Ryang YM, Krieg SM, Zimmer C, Meyer B, Ringel F (2013) Postoperative ischemic changes following resection of newly diagnosed and recurrent gliomas and their clinical relevance. J Neurosurg 118:801-808. https://doi.org/10.3171/2012.12.JNS12125

15. Glantz MJ, Cole BF, Forsyth PA, Recht LD, Wen PY, Chamberlain MC, Grossman SA, Cairncross JG (2000) Practice parameter: anticonvulsant prophylaxis in patients with newly diagnosed brain tumors. Report of the Quality Standards Subcommittee of the American Academy of Neurology. Neurology 54:1886-1893

16. Gokhale S, Khan SA, Agrawal A, Friedman AH, McDonagh DL (2013) Levetiracetam seizure prophylaxis in craniotomy patients at high risk for postoperative seizures. Asian J Neurosurg 8:169-173. https://doi.org/10.4103/1793-5482.125658

17. Herman ST, Abend NS, Bleck TP, Chapman KE, Drislane FW, Emerson RG, Gerard EE, Hahn CD, Husain AM, Kaplan PW, LaRoche SM, Nuwer MR, Quigg M, Riviello JJ, Schmitt SE, Simmons LA, Tsuchida TN, Hirsch LJ, Critical Care Continuous EEGTFotACNS (2015) Consensus statement on continuous EEG in critically ill adults and children, part II: personnel, technical specifications, and clinical practice. J Clin Neurophysiol 32:96108. https://doi.org/10.1097/WNP.0000000000000165

18. Hirsch LJ, LaRoche SM, Gaspard N, Gerard E, Svoronos A, Herman ST, Mani R, Arif H, Jette N, Minazad Y, Kerrigan JF, Vespa P, Hantus S, Claassen J, Young GB, So E, Kaplan PW, Nuwer MR, Fountain NB, Drislane FW (2013) American Clinical
Neurophysiology Society's standardized Critical Care EEG Terminology: 2012 version. J Clin Neurophysiol 30:1-27. https:// doi.org/10.1097/WNP.0b013e3182784729

19. Hwang SL, Lin CL, Lee KS, Lieu AS, Kuo TH, Chang CZ, Yen CP, Lin CK, Loh JK, Huang TY, Howng SL (2004) Factors influencing seizures in adult patients with supratentorial astrocytic tumors. Acta Neurochir 146:589-594: discussion 594. https://doi.org/10.1007/ s00701-004-0266-8

20. Iuchi T, Kuwabara K, Matsumoto M, Kawasaki K, Hasegawa Y, Sakaida T (2015) Levetiracetam versus phenytoin for seizure prophylaxis during and early after craniotomy for brain tumours: a phase II prospective, randomised study. J Neurol Neurosurg Psychiatry 86:1158-1162. https://doi.org/10.1136/jnnp-2014308584

21. Joiner EF, Youngerman BE, Hudson TS, Yang J, Welch MR, McKhann GM, 2nd, Neugut AI, Bruce JN (2018) Effectiveness of perioperative antiepileptic drug prophylaxis for early and late seizures following oncologic neurosurgery: a meta-analysis. J Neurosurg:1-9. doi:https://doi.org/10.3171/2017.10.JNS172236

22. Jordan KG (1993) Continuous EEG and evoked potential monitoring in the neuroscience intensive care unit. J Clin Neurophysiol 10: 445-475

23. Klimek M, Dammers R (2010) Antiepileptic drug therapy in the perioperative course of neurosurgical patients. Curr Opin Anaesthesiol 23:564-567. https://doi.org/10.1097/ACO. 0b013e32833e14f2

24. Leitinger M, Beniczky S, Rohracher A, Gardella E, Kalss G, Qerama E, Hofler J, Hess Lindberg-Larsen A, Kuchukhidze G, Dobesberger J, Langthaler PB, Trinka E (2015) Salzburg consensus criteria for non-convulsive status epilepticus-approach to clinical application. Epilepsy Behav 49:158-163. https://doi.org/10.1016/j. yebeh.2015.05.007

25. Lonjaret L, Guyonnet M, Berard E, Vironneau M, Peres F, Sacrista S, Ferrier A, Ramonda V, Vuillaume C, Roux FE, Fourcade O, Geeraerts T (2017) Postoperative complications after craniotomy for brain tumor surgery. Anaesth Crit Care Pain Med 36:213-218. https://doi.org/10.1016/j.accpm.2016.06.012

26. Manaka S, Ishijima B, Mayanagi Y (2003) Postoperative seizures: epidemiology, pathology, and prophylaxis. Neurol Med Chir (Tokyo) 43:589-600 discussion 600

27. Marcuse LV, Lancman G, Demopoulos A, Fields M (2014) Nonconvulsive status epilepticus in patients with brain tumors. Seizure 23:542-547. https://doi.org/10.1016/j.seizure.2014.04.003

28. Milligan TA, Hurwitz S, Bromfield EB (2008) Efficacy and tolerability of levetiracetam versus phenytoin after supratentorial neurosurgery. Neurology 71:665-669. https://doi.org/10.1212/01.wnl. 0000324624.52935 .46

29. Pandian JD, Cascino GD, So EL, Manno E, Fulgham JR (2004) Digital video-electroencephalographic monitoring in the neurological-neurosurgical intensive care unit: clinical features and outcome. Arch Neurol 61:1090-1094. https://doi.org/10. 1001/archneur.61.7.1090

30. Shan X, Fan X, Liu X, Zhao Z, Wang Y, Jiang T (2018) Clinical characteristics associated with postoperative seizure control in adult low-grade gliomas: a systematic review and meta-analysis. Neuro-Oncology 20:324-331. https://doi.org/ 10.1093/neuonc/nox130

31. Shaw MD, Foy PM (1991) Epilepsy after craniotomy and the place of prophylactic anticonvulsant drugs: discussion paper. J R Soc Med 84:221-223

32. Sirven JI, Wingerchuk DM, Drazkowski JF, Lyons MK, Zimmerman RS (2004) Seizure prophylaxis in patients with brain tumors: a meta-analysis. Mayo Clin Proc 79:1489-1494. https:// doi.org/10.4065/79.12.1489

33. Skardelly M, Brendle E, Noell S, Behling F, Wuttke TV, Schittenhelm J, Bisdas S, Meisner C, Rona S, Tatagiba MS, 
Tabatabai G (2015) Predictors of preoperative and early postoperative seizures in patients with intra-axial primary and metastatic brain tumors: a retrospective observational single center study. Ann Neurol 78:917-928. https://doi.org/10.1002/ana. 24522

34. Tan ZR, Long XY, Yang ZQ, Huang J, Hu QY, Yang HD, Li GL (2017) Younger age at surgery and lesser seizure frequency as prognostic factors for favorable seizure-related outcome after glioma resection in adults. Oncotarget 8:93444-93449. https://doi.org/10. 18632/oncotarget. 18726

35. Wang DD, Deng H, Hervey-Jumper SL, Molinaro AA, Chang EF, Berger MS (2017) Seizure outcome after surgical resection of insular glioma. Neurosurgery. https://doi.org/10.1093/ neuros/nyx 486

36. Waziri A, Claassen J, Stuart RM, Arif H, Schmidt JM, Mayer SA, Badjatia N, Kull LL, Connolly ES, Emerson RG, Hirsch LJ (2009) Intracortical electroencephalography in acute brain injury. Ann Neurol 66:366-377. https://doi.org/10.1002/ana.21721
37. Woo PY, Chan DT, Chan KY, Wong WK, Po YC, Kwok JC, Poon WS (2015) Risk factors for seizures and antiepileptic drugassociated adverse effects in high-grade glioma patients: a multicentre, retrospective study in Hong Kong. Surg Pract 19:2-8. https://doi.org/10.1111/1744-1633.12102

38. Wu AS, Trinh VT, Suki D, Graham S, Forman A, Weinberg JS, McCutcheon IE, Prabhu SS, Heimberger AB, Sawaya R, Wang X, Qiao W, Hess K, Lang FF (2013) A prospective randomized trial of perioperative seizure prophylaxis in patients with intraparenchymal brain tumors. J Neurosurg 118:873-883. https://doi.org/10.3171/ 2012.12.JNS111970

Publisher's note Springer Nature remains neutral with regard to jurisdictional claims in published maps and institutional affiliations. 